Ciência e Natura, v. 37 Part 2 2015, p. 162-167

ISSN impressa: 0100-8307 ISSN on-line: 2179-460X

\title{
ciênciaenatura
}

\section{Voltage Stability Improvement By Using FACTS Elements With Economic Consideration}

\author{
Hadi Kianersi ${ }^{1}$, Hamid Asadi ${ }^{2}$
}

${ }^{1}$ Iran, Isfahan, Islamic Azad University, Freidan Branch

${ }_{2}^{2}$ Iran, Isfahan, Islamic Azad University, Freidan Branch

\begin{abstract}
In last two decades due to increasing power demand power systems are operated to their maximum operation conditions. It will cause to any problems that one of these is voltage instability. To overcome this problem Flexible AC Transmission Systems(FACTS) have been used in power systems. The FACTS devices improves system stability, reduce losses and power generation cost. Best location of FACTS devices will help to maintain bus voltages at desired level, reduce cost of these devices and improve voltage stability margins. This paper presents the methods to location and rating of FACTS devices are optimized with using weighted coefficients method and Sterength Paretto Evolutionary Algorithm(SPEA).Thyristor controlled series capacitor(TCSC)and Static Var Compensator(SVC)are also considered in this paper.
\end{abstract}

Keywords: SVC,TCSC, voltage stability, GA and SFL, paretto algorithm 


\section{Introduction}

$\mathrm{I}$ ncreasing power demand due to increase $n$ population and develop industries cause some transmission networks heavily loaded. Therefore these networks will lead to voltage instability and increase losses. There are many conventional controllers such as transformer tap changers avd phase shifters which are used for improving voltage stability. But these controllers are not fast in response and have so many limitation. To avoid these drawbacks FACTS devices are proposed to get fast response and also use to study voltage stability in the power system. The voltage magnitude, phase angle and line impedance of the transmission line can change by using FACTS elements. The following factors are to be considered in the optimal installation and working range of different FACTS controllers, they are power loss reduction,stability improvement and considering the cost of facts devices[3]. recently new algorithms have developed to optimal location and operating range of FACTS controllers. Genetic Algorithm(GA) , particle Swarm Optimization and pareto algorithm. In this paper we deal with the application of pareto and weighted coefficient methods for the placement of TCSC\&SVC of FACTS controllers with considering voltage stability improvement and reduction active power loss and cost of these elements. In weighted coefficient method convert multi optimization problem(MOP) to Single Optimization Problem(SOP) and in continuation SOP will solve with Shuffle Frog Leapping(SFL) and GA algorithms

\section{Optimization methods}

\section{2-1-weighted coefficient}

F In this method by linear synthesis of Multi Objective Function(MOP)problemconverted to single optimization problem(SOP). Then we can use of SOP improvement methods to solve the problem.

$\min : y=f(\vec{x})=w_{1} \cdot f_{1}(\vec{x})+w_{2} \cdot f_{2}(\vec{x})+\ldots+w_{k} \cdot f_{k}(\vec{x})$

Here a problem with 3 objective function is formulated which include the minimization of voltage stability index(F1), active power loss(F2) and cost of FACTS devices installation(F3).In this paper the objective is to find the optimal location and operating range of different FACTS devices.Better results can be obtained by minimizing all the objective functions.

\section{2-1-1-Voltage stability index:}

A To study voltage stability used than differ indicies[8],[9],[10].In this paper to study of installing facts devices effects on voltage stability use than voltage stability index.This index for load buses can be expressed as:

$\mathrm{L}_{\mathrm{j}}=\left|1-\sum_{\mathrm{i}=1}^{\mathrm{n}_{\mathrm{g}}} \mathrm{F}_{\mathrm{ji}} \frac{\mathrm{V}_{\mathrm{i}}}{\mathrm{V}_{\mathrm{j}}}\right|$

ng is number of generator buses, also vi is voltage size in generator buses and vi is voltage size in load buses, Fji is calculated by using of network Admitance matrix as:

$\mathrm{Fji}=-[\mathrm{YLL}]^{-1}[\mathrm{YLG}]$

Where YLL,YLG are parts of network Admitance matrix.Therefor first objective function determined as:

$\mathrm{F} 1=\min \{\mathrm{Lj}\}$

The $\mathrm{L}$ index gives a scalar number to each load bus. If the index value ( $\mathrm{L}$ index) is moving towards zero, then the system is considered as stable and also improves system security. When this index value moves away from zero, the stability of system is relatively decreases then the system is considered as unstable.

\section{2-1-2-Reduce active power losses:}

One of the other FACTS devices installation advantage is reduce active power loss in power system. These devices with compensate reactive power could improve system power factor,hence can cause reduction system losses.This value can obtain as:

$P_{\text {loss }}=\sum_{i=1}^{n_{b}} R_{i}\left|I_{i}\right|^{2}$

Hence second objective function recommend as:

$\mathrm{F} 2=\min \{$ Ploss $\}$

\section{2-1-3-Minimize final cost of FACTS devices:}

In this paper final price of using FACTS elements must be minimized.Thus third objective function defined as:

$\mathrm{F} 3=\min \{\mathrm{CFACTS}\}$ 
Where CFACTS is final price in one parameter installation of FACTS devices with determined capacity.this price calculated by help of follow relations:

$C_{S V C}=0.13 S^{2}-0.3051 S+127.38 U S \$ / K V A R$

$C_{T C S C}=0.11 S^{2}-0.15 S+144 U S \$ / K V A R$

In (8),(9) $S$ is the capacity of FACTS elements in KVARHence the objective function is coded as:

$\mathrm{F}(\mathrm{x})=\max (\mathrm{Lj})+\min ($ Losses $)+\min ($ Cost $)$

Now must be optimize this function.

\section{Numerical results:}

In this paper used than 14 bus IEEE system.Before optimizing, the value of total active power loss and voltage stability index in buses stated in bellow table.

Table 1: voltage stability index and system losses before use facts devices.

\begin{tabular}{c|c} 
Load bus number & Stability $\operatorname{Index}\left(\mathbf{L}_{\mathbf{j}}\right)$ \\
\hline 4 & 0.1231 \\
\hline 5 & 0.207 \\
\hline 7 & 0.1326 \\
\hline 9 & 0.1315 \\
\hline 10 & 0.463 \\
\hline 11 & 0.1238 \\
\hline 12 & 0.1243 \\
\hline 13 & 0.1299 \\
\hline 14 & 0.1516 \\
\hline Total Loss & $14.68 \mathrm{MW}$ \\
\hline
\end{tabular}

according this table bus 10 is in worst position in aspect of voltage stability index. Optimization problem one more is done for TCSC and again for SVC placement by using of weight coefficient and pareto algorithms.

3-1Optimal placement of TCSC and SVC results with weighted coefficients:

In this part optimization problem is solving by GA and SFL and performed with different weight coefficients. Table $(2,3)$ show simulation results. as it shown SFL algorithm for different weight coefficient correlated each in equal amount. In this part TCSC capacity considered between $0 / 2$ to $-0 / 2$ line capability which installed on it.

Table 2: TCSC placement for different weighted coefficient

\begin{tabular}{|c|c|c|c|c|}
\hline Location & 20 & \multicolumn{2}{|c|}{1} & 4 \\
\hline Capacity & -0.156 & \multicolumn{2}{|c|}{-0.195} & -0.088 \\
\hline F1 & 0.077 & \multicolumn{2}{|c|}{0.077} & 0.080 \\
\hline F2 & 13.57 & \multicolumn{2}{|c|}{13.44} & 13.47 \\
\hline F3 & 153.6 & \multicolumn{2}{|c|}{145.7} & 143.6 \\
\hline W1 & 10 & \multicolumn{2}{|c|}{1} & 1 \\
\hline W2 & 1 & \multicolumn{2}{|c|}{10} & 1 \\
\hline W3 & 1 & \multicolumn{2}{|c|}{1} & 10 \\
\hline \multirow{2}{*}{$\begin{array}{l}\text { Iteration } \\
\text { number }\end{array}$} & GA & 190 & 186 & 166 \\
\hline & SFL & 110 & 100 & 95 \\
\hline
\end{tabular}

Results of table2 illustrates that, with change weight coefficient, different answers results. this state indicate that output of this method is more sensitive to weight coefficients. Reality their selection depend to weight coefficients.

According above table, with first weight coefficient, system have been more reduced toward the other states. but other answers have been noticeable reduced in compare with stability coefficient before TCSC installation. In second answer main is reduction in system losses and in third answer have lowest finally price.

Table (3) show simulation results for SVC. as shown SFL algorithm is more rapid than GA algorithm but in each case both method have been correlated each other equally. In this simulation SVC capacity considered between 100 Mvar to 100. 
Table 3: svc placement for different weighted coefficient

\begin{tabular}{|c|c|c|c|c|}
\hline \multicolumn{2}{|c|}{ Location } & 9 & 9 & 1 \\
\hline \multicolumn{2}{|c|}{ Capacity } & -58.33 & -30.42 & 31.14 \\
\hline \multicolumn{2}{|c|}{ F1 } & 0.064 & 0.069 & 0.080 \\
\hline \multicolumn{2}{|c|}{ F2 } & 13.64 & 13.39 & 13.46 \\
\hline \multicolumn{2}{|c|}{ F3 } & 152.06 & 152.45 & 146.61 \\
\hline \multicolumn{2}{|c|}{ W1 } & 10 & 1 & 1 \\
\hline \multicolumn{2}{|c|}{ W2 } & 1 & 10 & 1 \\
\hline \multicolumn{2}{|c|}{ W3 } & 1 & 1 & 10 \\
\hline \multirow{2}{*}{$\begin{array}{c}\text { Iteration } \\
\text { number }\end{array}$} & GA & 200 & 135 & 140 \\
\hline & SFL & 115 & 95 & 180 \\
\hline
\end{tabular}

Table3 results show that similar to TCSC locationing part has been reached to different answer sheet, this case shows that above improvement problem is more sensitive to weight coefficient.In reality selection of weight coefficient done with respect to system exploitor in spiteof this suitable selection these coefficient is more timing and pricing work in other aspect appears that with weight coefficient increase belong to one objective function amounts of objective function become less for of it,snormal amount. To solve this problem we purpose to using of pareto method.

\section{3-2-optimal location of TCSC \& SVC with pareto algorithm}

Sterength pareto evolutionary algorithm(SPEA) Algoritm was introduced in 1999 by zitzeloo and zill.This algoritm using of two meaning of best generation and undominate vector.In each generation undominate set maintain in archieve as foreign set and participating in inherited performance fitting amount of each chromosome in current population and foreign population depend on dominated solving ways.

With above descriptions SPEA algoritm performs in following way:

(1)elementary(early) generation $\mathrm{P}$ with $\mathrm{N}$ chromosom randomly and produce set as foreign set $\mathrm{P}^{\prime}$

2)Copy $P$ undominate solution methods in $P^{\prime}$

3)eliminate solution methods which being covered in $\mathrm{P}^{\wedge}$ 'with it,s members.
4)If number of stored undominate solutions in $\mathrm{P}^{\prime}$ is more than of predetermined maximum value, with using of clustering remedy foreign set .

5)Determine fitting value of P\&P'sets chromosoms.

6)Select next generation with rolluted whell or tonnument method of P+P'sets.

7)Apply cross over and mutation

8)If stop conditions is prepared, performance end neverless go to step2

a)To each solution method i $\epsilon \mathrm{P}^{\prime}$, realamountsi $\epsilon[0,1)$ wich is Called strength degree, is dedicated. si is fitted with number of population member $j \in P$ for $i>-j$. if $n$ is number of $\mathrm{p}$ chromosoms which is covered by each member of $i$ forigen set then si stated such as:

$\mathrm{Si}=\mathrm{n} /(\mathrm{N}+1)$

fitness of each chromosome with it,s strength degree is equal.

b) competent amount of each chromosome j $\epsilon \mathrm{p}$ is calculated with sum of solidity degree related to foreign undominate methods $\mathrm{j} \in \mathrm{P}^{\prime}$ that covers $j$. here we sum result (output) with1 till guranteeP' members have better fitness to P'members. notice that here purpose is minimizing.

$F j=1+\sum$ si where fje $[1, N)$

By helping of SPEA\&EP means, SPEA Algorithm in this paper for multipurpose improvement apply with 3 objective function.

In paretto algorithm by select 20 choromosom with 200 more run,table4,5 results. This method gives archive of responses that we can choice best of them. This is important advantage for pareto algorithm. some of these members are equal with response of weighted cofficent method that are specified as highlight.

Table 4archive members for SVC placement

\begin{tabular}{|c|c|c|c|c|c|}
\hline \multirow{2}{*}{$\begin{array}{c}\begin{array}{c}\text { Member } \\
\text { No. }\end{array} \\
1\end{array}$} & \multicolumn{2}{|c|}{ SVC } & F1 & F2 & F3 \\
\hline & 1 & 31.14 & 0.08 & 13.56 & 144.61 \\
\hline 2 & 9 & -58.33 & 0.064 & 13.64 & 152.06 \\
\hline 3 & 9 & -30.42 & 0.069 & 13.39 & 152.45 \\
\hline 4 & 1 & 25.58 & 0.08 & 13.56 & 144.61 \\
\hline 5 & 10 & -0.185 & 0.079 & 13.56 & 149.91 \\
\hline 6 & 2 & -93.77 & 0.08 & 13.56 & 145.84 \\
\hline 7 & 9 & -68.43 & 0.068 & 13.57 & 151.89 \\
\hline 8 & 2 & -78.85 & 0.08 & 13.56 & 145.84 \\
\hline
\end{tabular}




\begin{tabular}{c|c|c|c|c|c}
\hline 9 & 10 & -37.28 & 0.069 & 13.61 & 150.29 \\
\hline 10 & 10 & -8.132 & 0.0772 & 13.47 & 150.00 \\
\hline 11 & 10 & -4.04 & 0.078 & 13.51 & 149.96 \\
\hline 12 & 10 & -5.71 & 0.078 & 13.49 & 149.97 \\
\hline 13 & 10 & -30.43 & 0.071 & 13.52 & 150.23 \\
\hline 14 & 10 & -35.06 & 0.070 & 13.57 & 150.27 \\
\hline 15 & 9 & -39.19 & 0.067 & 13.40 & 152.34 \\
\hline 16 & 10 & -44.68 & 0.068 & 13.73 & 150.35 \\
\hline 17 & 10 & -2.47 & 0.079 & 13.53 & 149.94 \\
\hline 18 & 10 & -41.24 & 0.069 & 13.67 & 150.32 \\
\hline 19 & 10 & -26.33 & 0.072 & 13.48 & 150.19 \\
\hline 20 & 9 & -42.14 & 0.067 & 13.41 & 152.30
\end{tabular}

and improvement voltage stability converting to a multi optimization problem then this problem solving with shuffle frog leaping and genetic algorithm. Then use than pareto method to optimization. Results have shown that SVC and TCSC enhanced voltage profile at all buses and minimizing generation cost and active power losses. Also this paper has identified that pareto algorithm gives archive of responses that we can choice one the best of them.

\section{References}

S. Durairaj, P.S. Kannan and D. Devaraj, "Application of Genetic Algorithm to Optimal Reactive Power Dispatch including Voltage Stability Constraint," Journal of Energy \& Environment, vol. 4, April,2005.

P.Kundur, Power System Stability and Control, Mc. Graw Hill, New York, 1994.

V.A.Preethi,Dr.S.Muralidharan,MrS.Rajasekar," Application of Genetic Algorithm to Power System Voltage Stability Enhancement Using Facts Devices', 2011 International Conference on Recent Advancements in Electrical, Electronics and Control Engineering

Stephane Gerbex, Rachid Cherkaoui, and Alain J. Germond, "Optimal Location of Multi-Type FACTS Devices in a Power System by Means of Genetic Algorithms," IEEE Trans. Power Systems, vol. 16, pp. 537-544, August 2001.

Pierre Paterni, Sylvain Vitet, and Michel Bena, "Optimal Location of Phase Shifters in the French Network by Genetic Algorithm," IEEETrans. Power Systems, vol. 14, pp. 37-42, February 1999.

G.I.Rashed, H.I.Shaheen, and S.J.Cheng, "Optimal Location andParameter Setting of TCSC by Both Genetic Algorithm and Particle Swarm Optimization," 2007 Second IEEE Conference on Industrial Electronics and Applications , pp. 1141-1147.

Li Zhihuan; Li Yinhong; Duan Xianzhong, Improved Strength Pareto Evolutionary Algorithm with Local Search Strategies for Optimal Reactive Power Flow Information Technology Journal;2010, Vol. 9 Issue 4, p749.

In this paper location of SVC and TCSC with considering reduce system active power losses

A. Mohamed and G.B.Jasmon, "Determining the Weak Segment of a Power System with 
Voltage Stability Considerations," Electric Machines and Power Systems-24:555-568, 1996.

Michael Merkle, Atsushi Harada, Rajiv Kumar and Amir M. Miri," Investigation of Voltage Stability of the IEEE 14 Bus Power System and Enhancement with 100 MVAR STATCOM - A Simulation Study," Conference and Exhibition on Power Generation, Transmission, Distribution and Energy Conversion MED POWER 2002National Technical University of Athens, pp. 4 - 6, November 2002.

P.Kessel and H.Glavitsh, "Estimating the Voltage Stability of a Power System," IEEE Transaction on Power Delivery, vol. 3, PWRD-1,July 1986.

D. Thukaram, S. Lakpathi, K. Ravishankar and S. Surendra, "Reactive Power Optimization with different Objectives in Large Power Systems including HVDC Systems and FACTS devices," Third International Conference on Power Systems, Kharagpur, INDIA, December 2009.

H.R.Baghaee, M.Jannati and B.Vahidi, "Improvement of Voltage Stability and Reduce Power System Losses by Optimal GAbased Allocation of Multi-type FACTS Devices," Eleventh International Conference on Electrical and Electronic Equipment, OPTIM, pp. 209-214, May 2008.

E. Zitzler and L. Thiele, "An Evolutionary Algorithm for Multi objective optimization: The Strength Pareto Approach," Swiss Federal Institute of Technology, TIK-Report, No. 43, 1998. 